\title{
Green Approach for In-Situ Growth of CdS Nanorods in Low Band Gap Polymer Network for Hybrid Solar Cell Applications
}

\author{
Ramil K. Bhardwaj1,2, Vishal Bharti', Abhishek Sharma1, Dibyajyoti Mohanty', \\ Vikash Agrawal', Nakul Vats ${ }^{3}$, Gauri D. Sharma', Neeraj Chaudhary ${ }^{1}$, Shilpa Jain ${ }^{1}$, \\ Jitender Gaur ${ }^{1 *}$, Kamalika Banerjee ${ }^{2}$, Suresh Chand ${ }^{*}$ \\ ${ }^{1}$ Physics of Energy Harvesting, CSIR-National Physical Laboratory, New Delhi, India \\ ${ }^{2}$ School of Science, India Gandhi National Open University, New Delhi, India \\ ${ }^{3} \mathrm{~J} \&$ S Research and Innovations, Delhi, India \\ Email: ${ }^{*}$ iitender.jnsri@gmail.com, ${ }^{*}$ schand@mail.nplindia.org
}

Received 8 May 2014; revised 23 June 2014; accepted 6 July 2014

Copyright (C) 2014 by authors and Scientific Research Publishing Inc.

This work is licensed under the Creative Commons Attribution International License (CC BY). http://creativecommons.org/licenses/by/4.0/

(c) (i) Open Access

\section{Abstract}

In-situ growth of CdS nanorods (NRs) has been demonstrated via solvothermal, in a low band gap polymer, poly [[4,8-bis[(2-ethylhexyl)oxy] benzo [1,2-b:4,5-b'] dithiophene-2,6-diyl] [3-fluoro-2[(2-ethylhexyl) carbonyl] thieno [3,4-b] thiophenediyl]] (PTB7). It is a high yielding, green approach as it removes use of volatile and hazardous chemicals such as pyridine as ligand which are conventionally used to synthesize precursors of CdS (NRs). Moreover the solvothermal process is a zero emission process being a close vessel synthesis and hence no material leaching into the atmosphere during the synthesis. The PTB7:CdS nanocomposite has been characterized by SEM, XRD, FTIR, UV-visible spectroscopy techniques. The photoluminescence (PL) spectroscopy study of PTB7 with CdS NRs has shown significant PL quenching by the incorporation of CdS NRs in PTB7; this shows that CdS NRs are efficient electron acceptors with the PTB7. The PTB7:CdS is used as active layer in the fabrication of hybrid solar cells (HSC) as donor-acceptor combination in the bulk heterojunction (BHJ) geometry. The HSCs fabricated using this active layer without any additional supporting fullerene based electron acceptor has given power conversion efficiency of above $1 \%$.

\section{Keywords}

CdS Nanorods, PTB7, In-Situ Growth, Solvothermal, Hybrid Solar Cell

${ }^{*}$ Corresponding authors.

How to cite this paper: Bhardwaj, R.K., Bharti, V., Sharma, A., Mohanty, D., Agrawal, V., Vats, N., Sharma, G.D., Chaudhary, N., Jain, S., Gaur, J., Banerjee, K. and Chand, S. (2014) Green Approach for In-Situ Growth of CdS Nanorods in Low Band Gap Polymer Network for Hybrid Solar Cell Applications. Advances in Nanoparticles, 3, 106-113.

http://dx.doi.org/10.4236/anp.2014.33015 


\section{Introduction}

The fourth generation solar cells are based on the bulk heterojunction (BHJ) active layers of the inorganic nanomaterials and organic polymers [1]-[7]. In this evolutionary geometry of solar cells the cadmium sulfide (CdS) nanomaterials have emerged as one of the most economical and efficient electron acceptor material. These materials enjoy two interesting features of their chemical and physical properties, viz., their synthesis can be easily tailored to obtain desired morphology and they exhibit enhanced optical, electronic, photo-conducting and luminescent properties [1]-[22]. The composite of CdS and organic polymers show accelerated charge transfer rates due to the chemical interactions between the CdS and the organic polymer functional groups, making them optimum material for electron acceptor applications in hybrid solar cells (HSC) [1]-[22]. Several synthetic strategies for CdS nanomaterials have been demonstrated in the literature for various morphologies such as sol-gel, solvothermal, solution phase and co-precipitation [7]-[10] [16]-[27]. Their morphology plays a critical role in their performance and the efficiency of HSC [10] [12] [13] [19]. Conventionally the synthetic processes utilizes biologically hazardous chemicals such as pyridine to synthesize precursor cadmium complexes for CdS along with several surfactants to control morphology of the nanomaterials. This causes poor atom economy of the reactions and several environmental hazardous [20]-[22]. In our previous work we have highlighted this aspect and demonstrated green synthesis of CdS Quantum Dots (QDs) in-situ growth in the P3HT polymer network [10]. Here we replaced pyridine with triethyl amine as co-ligand for the synthesis of precursor cadmium complex. However, due to the poor solubility of the P3HT:CdS QDs nano-composite in the non-polar organic solvents such as chlorobenzene efficient solar cell could not be obtained due to the poor quality of thin films of the composite [10] [11]. In our present work we focus on the solubility of the polymer:CdS composite in nonpolar solvents and take the green aspect in the synthesis to next higher level. Herein we demonstrate, in-situ growth of CdS nanorods (NRs) in the matrix of polymer poly [[4,8-bis[(2-ethylhexyl)oxy]benzo[1,2-b:4,5-b’] dithiophene-2,6-diyl][3-fluoro-2-[(2-ethylhexyl)carbonyl]thieno[3,4-b]thiophenediyl]] (PTB7) via solvothermal process followed by the fabrication of HSC using the PTB7:CdS as donor-acceptor combination in BHJ geometry. The novelty of this work arises from the solvothermal in-situ growth of CdS NRs in a low band gap polymer. Due to which lower temperature was required to thermally decompose precursor cadmium complex into CdS NRs. This protects the polymer from thermal degradation as well as allows chemical bonding between the functional groups of the polymer and the CdS which is observed in the significant decrease in the band gap of PTB7 from $1.7 \mathrm{eV}$ to $1.59 \mathrm{eV}$. Another important feature of this work is the choice of the ligand for precursor cadmium complex that works as a source of sulfur and easily decomposes to the CdS. Here we used dithiocarbamate of chloroaniline. The dithiocarbamates are well known for the thermal degradation into CdS nanomaterials. The chloroaniline ring in this dithiocarbamate gives high solubility to the complex in non-polar solvents such as chlorobenzene. Also chloroaniline was used in place of pyridine/triethyl amine as co-ligand for the complex. This solved couple of serious issues related with the CdS synthesis, 1) the chloro-aniline being nonvolatile at room temperature does not leach into the atmosphere during reaction work up and hence greener material as compared to pyridine and triethyl anime; 2) due to structural similarity of the chloro-aniline with chlorobenzene the complex is soluble in the non-polar solvent. The requirement for the solubility of BHJ layer in the non-polar solvents is subjected to the fabrication procedure of the HSCs. The BHJ layer is coated on hydrophilic hole transport layer and hence the lower layer should not be disturbed while coating of the BHJ layer. Also it has been well observed that due to optimum evaporation rate and some other features the chlorobenzene is among the best solvents for good texture of the thin BHJ film. The PTB7:CdS NRs composite is characterized by TEM, SEM imaging, XRD, FTIR, UV-Visible spectroscopy techniques. Homogenous distribution of CdS NRs in PTB7 matrix was observed from TEM and SEM images of PTB7:CdS. The photoluminescence (PL) study of the PTB7:CdS shows significant quenching of the PL of PTB7 due to incorporation of CdS NRs in PTB7. 1:1 (w/w) ratio of PTB7:CdS shows optimum quenching of PL of the PTB7. These findings lead us to prepared HSC using PTB7:CdS in 1:1 and 1:0.05 (w/w) ratios as donor-acceptor combination in BHJ geometry. The champion results came up from the 1:1 ratio having power conversion efficiency (PCE) of the 1.22\%, however the average PCE observed for the same ratio was $1.16 \%$.

\section{Experimental}

\subsection{General Procedures}

Cadmium acetate dihydrate and carbon disulfide were procured from Sigma Aldrich. Polymer PTB7 was pur- 
chased from One-Materials, USA. All the reagents used were of AR grade procured from Merck, India. Melting points were determined using a Thomas Hoover melting point apparatus and are uncorrected. Mass spectra were recorded on a Hybrid Quadrupole-TOF LCIMS $\backslash$ MS mass spectrometer (Q. Star XL) The reactions were monitored by Thin Layer chromatography (TLC) using aluminium sheets with silica gel $60 \mathrm{~F}_{254}$ (Merck). FTIR spectra of all the molecules were recorded in $\mathrm{KBr}$ pellets on a Perkin-Elmer spectrum 2000 FTIR spectrometer. Elementar Analysensysteme Gmbh Vario El-III instrument was used for CHNS elemental analysis. TG/DTG curves were simultaneously recorded on PerkinElmer Model TGA-7, USA, under a nitrogen atmosphere at a heating rate of $10^{\circ} \mathrm{C} \cdot \mathrm{min}^{-1}$ from $20^{\circ} \mathrm{C}$ to $800^{\circ} \mathrm{C}$. Transmission electron microscope (TEM) was recorded on Tecnai G2 F30 STWIN. Sample for TEM of the polymer was prepared by suspending $\mathrm{P}_{\mathrm{A} 1}$ in methanol by using ultrasonication at $45 \mathrm{kHz}$ for $15 \mathrm{~min}$ and loading them onto the copper grids for TEM.

\subsection{Synthesis of Sodium Salt of $p$-Chloroaniline Dithiocarbamate (NaPCD)}

PCA (100 mmol) was dissolved in ethanol $(20 \mathrm{ml})$ with $\mathrm{NaOH}(100 \mathrm{mmol})$ in a $100 \mathrm{~mL}$ flask. This solution was added drop wise in a bath containing $\mathrm{CS}_{2}(500 \mathrm{mmol})$ maintained at room temperature. After $4 \mathrm{~h}$, the excess amount of $\mathrm{CS}_{2}$ was removed using rotary evaporator to collect sodium salt of $p$-chloroaniline dithiocarbamate (NaPCD). The product was repeatedly washed with ethanol to remove any unreacted starting materials to afford the product as yellow solid (18.0 g, $80 \%$ yield). MS EI (m/z): $[\mathrm{M}]^{+}$and $[\mathrm{M}+2]^{+}$calcd for $\mathrm{NaC}_{7} \mathrm{H}_{5} \mathrm{NS}_{2} \mathrm{Cl}$ : 225.6960 and 227.6960; found: 225.4797 and 227.4844 respectively; Anal. Calcd for $\mathrm{NaC}_{7} \mathrm{H}_{5} \mathrm{NS}_{2} \mathrm{Cl}: \mathrm{C}=$ 37.251\%; $\mathrm{H}=2.233 \% ; \mathrm{N}=6.206 \%$; $=28.415 \%$; Found: $\mathrm{C}=37.011 ; \mathrm{H}=2.244 ; \mathrm{N}=6.322 ; \mathrm{S}=28.215$.

\subsection{Synthesis of Cadmium Complex, $\mathrm{Cd}(\mathrm{PCA})_{2}(\mathrm{PCD})_{2}$}

Cadmium (II) acetate $(10 \mathrm{mmol})$ with NaPCD $(20 \mathrm{mmol})$ and PCA $(20 \mathrm{mmol})$ was vigorously stirred for $1 \mathrm{hr}$ in methanol solvent. A yellow colored cadmium complex was collected by centrifugation, which was repeatedly washed with cold methanol and $\mathrm{CH}_{2} \mathrm{Cl}_{2}(4.63 \mathrm{~g}, 80 \%$ yield). Elemental analysis calculated for

$\mathrm{Cd}\left(\mathrm{C}_{6} \mathrm{H}_{6} \mathrm{NCl}\right)_{2}\left(\mathrm{C}_{7} \mathrm{H}_{5} \mathrm{NS}_{2} \mathrm{Cl}\right)_{2}: \mathrm{C}=40.400 \% ; \mathrm{H}=2.872 \%$; $\mathrm{N}=7.251 \% ; \mathrm{S}=16.592 \%$; Found: $\mathrm{C}=40.112 \% ; \mathrm{H}=$ $2.921 \% ; \mathrm{N}=7.102 \%$; $=16.222 \%$.

\subsection{Synthesis of PTB7:CdS NRs}

A homogenous solution of $250 \mathrm{mg} \mathrm{Cd}(\mathrm{PCA})_{2}(\mathrm{PCD})_{2}$ and $50 \mathrm{mg}$ PTB7 (one-materials, USA), was prepared in $20 \mathrm{ml}$ chlorobenzene by subjecting it to ultra sonication $(45 \mathrm{KHz})$ for $30 \mathrm{~min}$. The mixture was transferred into a TEFLON lined solvothermal bomb and kept at $150^{\circ} \mathrm{C}$ for 4 hrs. The resulting mixture was concentrated by evaporating the solvent under vacuum to $\sim 5 \mathrm{ml}$ solution volume. The concentrated solution was spin coated on glass surface and annealed at $200^{\circ} \mathrm{C}$ for 30 min under $\mathrm{N}_{2}$ atmosphere.

\subsection{Fabrication of HSC Devices}

The HSCs in the configuration ITO/PEDOT:PSS/PTB7:CdS/Al were fabricated as follows. ITO glass substrates were subsequently cleaned with detergent followed by treatment in ultrasonic bath using different solvents such as acetone, trichloroethylene and subsequently in isopropanol. The cleaned substrates were then annealed at $150^{\circ} \mathrm{C}$ in the vacuum oven for $20 \mathrm{~min}$. Now, the dried substrates were exposed to the UV ozone cleaning for 10 15 min. PEDOT:PSS (Sigma Aldrich, USA with 1.3\% dispersion in water) were spin cast on these cleaned substrates using digital spin coater with optimized spin rates for particular thickness. The substrates were dried at $140^{\circ} \mathrm{C}$ for $30 \mathrm{~min}$ in the vacuum oven and then transferred into a nitrogen filled glove box to deposit the active layer on the substrate using spin cast method. The mixture of PTB7:CdS in the chlorobenzene solvent in (w/w) ratios of 1:0.5 and 1:1. The active layer was spin casted and cured at $140^{\circ} \mathrm{C}$ for 20 min under nitrogen atmosphere in glove box. Finally, aluminum electrodes were deposited with thickness $120 \mathrm{~nm}$ inside the thermal evaporator chamber with the vacuum $8 \times 10^{-6}$ mbar through shadow mask. The active area of the pixel device was $\sim 0.075 \mathrm{~cm}^{2}$. The current density-voltage $(J-V)$ characteristics of the devices were recorded using Keithley 2420 Source Meter unit interfaced with a computer. These characteristics have been performed in the dark and under tungsten halogen lamp with illumination intensity of $1000 \mathrm{~W} / \mathrm{m}^{2}$. 


\section{Results and Discussions}

The CdS NRs were synthesized according to the procedure described in Scheme 1. The ligands and complex was as described in Section 2. The XRD spectra (Figure 1(a)) of CdS NRs, PTB7 and PTB7:CdS composite, indicating peaks corresponding to the crystalline planes [100], [002], [101], [102], [110], [103] and [112] for the CdS NRs and PTB7:CdS. It corresponds to the cubic crystalline character of the CdS NRs present in the polymer matrix. It establishes insertion of the CdS NRs in the matrix of the PTB7. The FTIR spectra of the PTB7:CdS, PTB7 and Cd(PCA $)_{2}(\mathrm{PCD})_{2}$ are given in Figure 1(b). The characteristic band for dithiocarbamate functional groups are at $1109 \mathrm{~cm}^{-1}$ with a shoulder $\sim 1018 \mathrm{~cm}^{-1}$ in $\mathrm{Cd}(\mathrm{PCA})_{2}(\mathrm{PCD})_{2}$ which indicates that the $\mathrm{S}=\mathrm{C}$-S group is acting as a bidentate ligand. The band at $1109 \mathrm{~cm}^{-1}$ is quite broad and has slight shoulder at $\sim 1200 \mathrm{~cm}^{-1}$ which may be attributed to the C-N group (here merged with that of the dithiocarbamate band due to resonance in the $\mathrm{N}-\mathrm{C}=\mathrm{S}$ group). The bands at 1640,1556 and $1415 \mathrm{~cm}^{-1}$ are assigned for the aromatic chloroaniline moiety in the PAC and PCD ligands. The comparison of the FTIR spectra of PTB7:CdS with that of $\mathrm{Cd}(\mathrm{PCA})_{2}(\mathrm{PCD})_{2}$, show a blue shift from $1109 \mathrm{~cm}^{-1}$ to $1088 \mathrm{~cm}^{-1}$ in the dithiocarbamate band along with the removal of the shoulder at $\sim 1018 \mathrm{~cm}^{-1}$. It has been explained in-terms of the formation of the CdS from thermal decomposition of the dithiocarbamate with the removal of $\mathrm{C}-\mathrm{N}$ and $\mathrm{S}-\mathrm{C}=\mathrm{S}$. Both the PTB7 and PTB7:CdS show bands $\sim 1110 \mathrm{~cm}^{-1}$ indicating $\mathrm{C}=\mathrm{S}$ bond present in the PTB7. However the $1110 \mathrm{~cm}^{-1}$ band in PTB7:CdS is showing a blue shift of $10 \mathrm{~cm}^{-1}\left(1120 \mathrm{~cm}^{-1}\right)$ indicating the ligation of the sulfur atom of C=S of PTB7 with the cadmium ions.

As earlier discussed cadmium complexes of dithiocarbamate are known to decompose into CdS nano materials of controlled morphologies which depend on the synthetic conditions such as temperature, pressure, solvent, surfactants etc. [15]. The source of CdS in present process is cadmium complex, Cd(PCA $)_{2}(\mathrm{PCD})_{2}$. The TG analysis (Figure 2(a)) of this material shows degradation of the complex into CdS at $200^{\circ} \mathrm{C}$ under nitrogen atmosphere. However under high pressure conditions of the solvothermal process the temperature required for the transformation into reduces [15]. This advantage of low temperature requirement is used here for in-situ growth of CdS NRs in the PTB7 matrix. The porous polymer structure provides sites for the growth of CdS NRs, also this additionally induces chemical bonding between the functional groups of the PTB7 and cadmium as depicted by the FTIR. The uniform distribution of CdS NRs in the PTB7 matrix is observed by the SEM and TEM images of the PTB7:CdS NRs (Figure 2(b) \& Figure 2(c)), respectively. The EDS (Figure 2(d)) indicates cadmium rich PTB7:CdS composite. Majority size of the CdS NRs is $10 \mathrm{~nm}$ TEM image (Figure 2(d)) of the PTB7:CdS shows $\sim 10 \mathrm{~nm}$ CdS NRs. The HRTEM image (Figure 2(d)) highlights the crystalline character of the CdS NRs in the PTB7 matrix. The fringe width of $\sim 3.8 \AA$ corresponding to $2 \theta_{[001]}=23.2^{\circ}$ is observed in HRTEM of the composite.

The UV-visible spectra (Figure 3(a)) of PTB7 shows absorption in the range of $\lambda=750 \mathrm{~nm}$ to $500 \mathrm{~nm}$, with peak at $680 \mathrm{~nm}$ and a shoulder at $\sim 630 \mathrm{~nm}$. The CdS NRs shows poor absorption in the visible range and may be seen as a plateau throughout the visible spectrum. As regards to the absorption of PTB7:CdS, there is a shift in the absorption band from $\sim 750 \mathrm{~nm}$ to $\sim 805 \mathrm{~nm}$. The value of the bad gap calculated from the absorption edges of the spectra of PTB7 in PTB7:CdS have been found to be $1.71 \mathrm{eV}$ and $1.59 \mathrm{eV}$, respectively. It clearly demon-

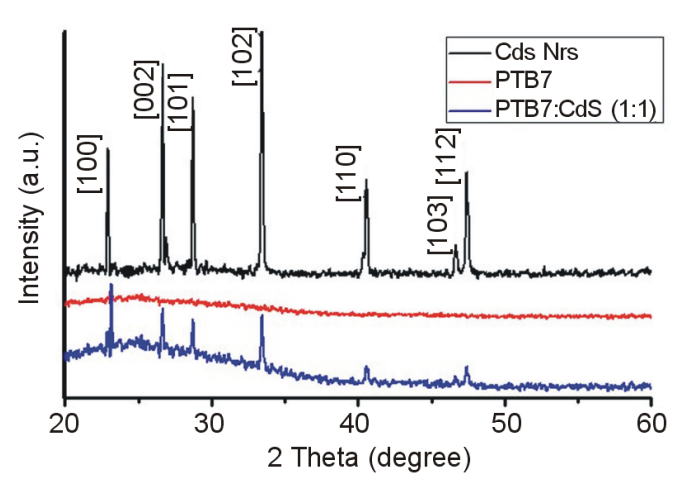

(a)

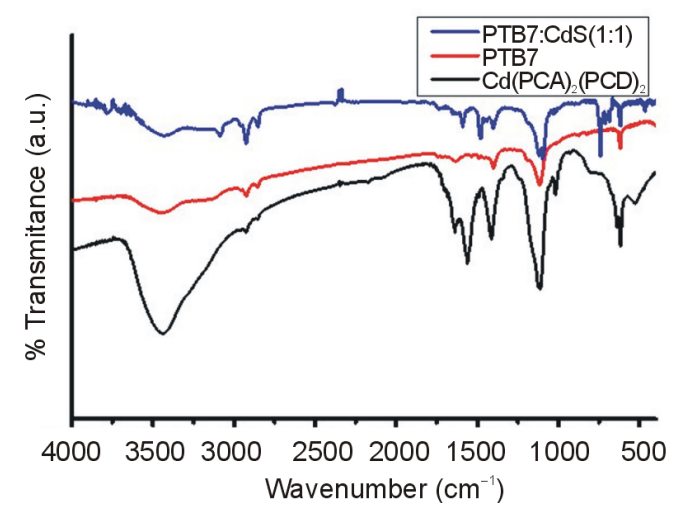

(b)

Figure 1. (a) Powder XRD of CdS NRs, PTB7, PTB7:CdS NR (1:1) (w/w) ratio; (b) FTIR spectra of PTB7:CdS NR (1:1) (w/w) ratio, PTB7, Cd(PCA $)_{2}(\mathrm{PCD})_{2}$. 

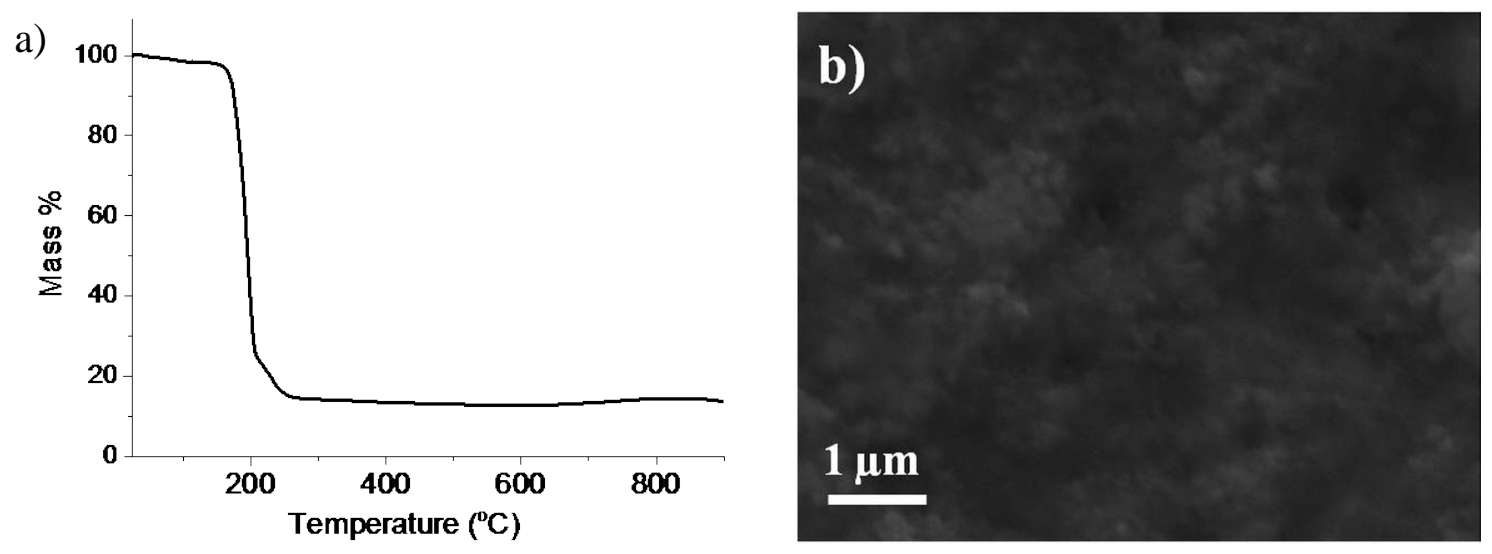

c)
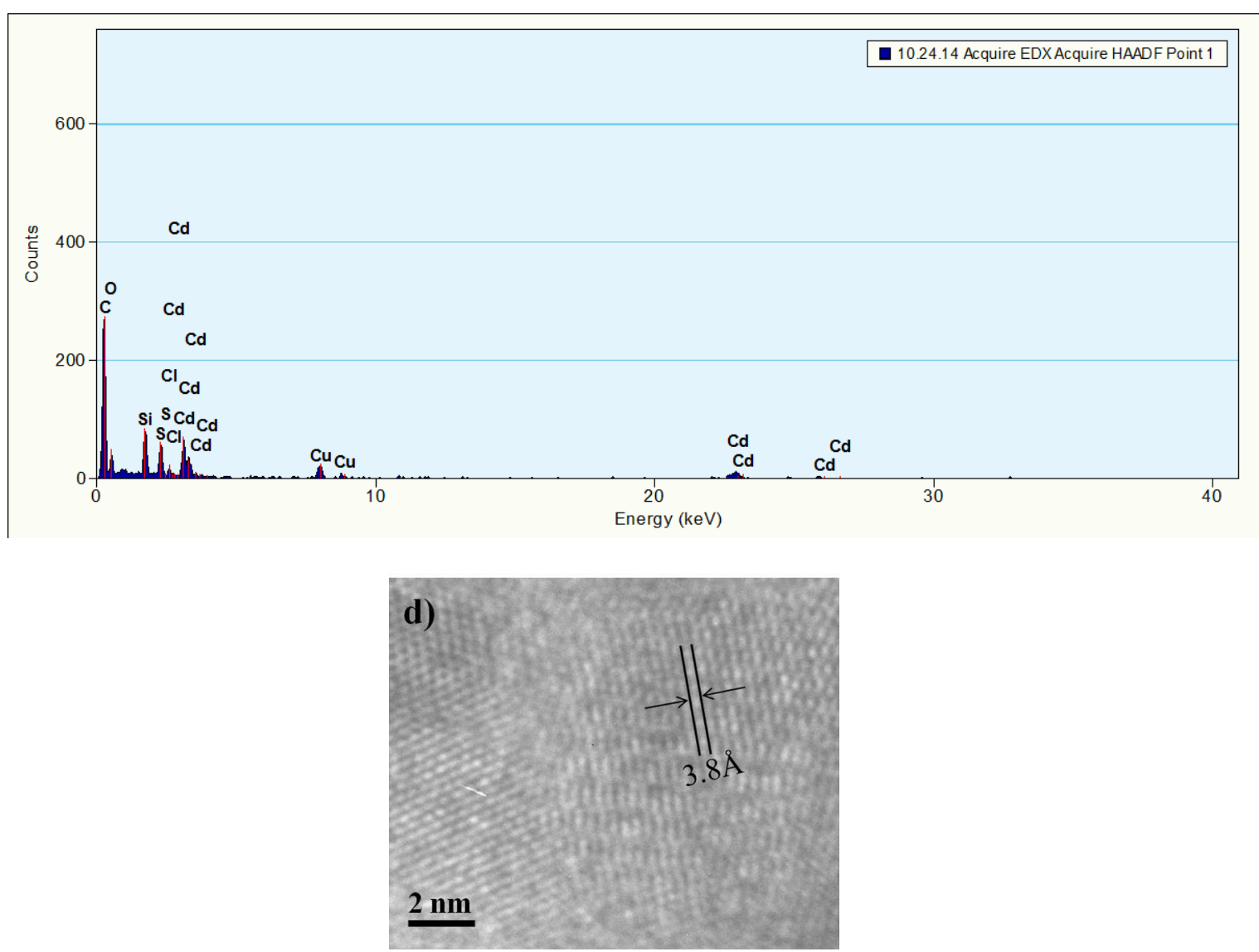

Figure 2. (a) TG analysis of $\mathrm{Cd}(\mathrm{PCA})_{2}(\mathrm{PCD})_{2}$ under $\mathrm{N}_{2}$ atmosphere, heating rate $10^{\circ} \mathrm{C} / \mathrm{min}$ showing formation of $\mathrm{CdS}$ at $200^{\circ} \mathrm{C}$; (b) SEM image of PTB7:CdS NR (1:1) (w/w) ratio, showing homogenous distribution of CdS NRs in PTB7 matrix; (c) EDS analysis of a selected area in the SEM, showing Cd rich composite; (d) HRTEM of the PTB7:CdS NRs (1:1) (w/w) ratio, showing the lattice plane distance corresponding to that of the $2 \theta_{[001]}=23.2^{\circ}$.

strates the decrease of $0.12 \mathrm{eV}$ in the band gap of PTB7 by the in-situ growth of CdS NRs. This effect is similar to the one observed when PTB7 is mixed with the highly expensive acceptor molecules such as ICBA and $\mathrm{PC}_{71} \mathrm{BM}$ [19]-[21]. The reduction in band gap of the PTB7:CdS would give an efficient solar cell as compared to the conventional approach where there is no decrease in band gap. It shows that the nanocomposite of the PTB7 and CdS NRs is suitable for the fabrication of HOISC devices.

To obtain the optimum ratio of the PTB7:CdS NRs for the BHJ active layer of the HSC PL quenching studies are conducted. The electron acceptor CdS NRs quenches the spectra due to the photoelectrons generated by the 
PTB7 for $\lambda_{\mathrm{ex}} 680 \mathrm{~nm}$ excitation (Figure 3(b)). Significant quenching is observed by the incorporation of CdS NRs in PTB7 even at low concentration of CdS NRs. Showing rapid charge transfer from the PTB7 to CdS NRs. With the increase in concentration of CdS NRs in PTB7 there is an increase in the quenching of PL of PTB7. However it saturates beyond 1:1 (w/w) ratio and further addition of CdS NRs does not show any significant increase in the quenching. Hence we used 1:0.5 and 1:1 concentrations for the fabrication of the BHJ active layer for the HSC fabrication.

The two HSC devices were fabricated in ITO/PEDOT:PSS/PTB7:CdS NRs/Al configuration with PTB7:CdS NRs (w/w) ratio of 1:0.5 and 1:1. The device $J-V$ characteristics are shown in Figure 3(c), where $J$ is current density in $\mathrm{mA} / \mathrm{cm}^{2}$ and $V$ is voltage in $\mathrm{V}$. The important device parameters derived from these characteristics are open circuit voltage $\left(\mathrm{V}_{\mathrm{oc}}\right)$, short circuit current density $\left(\mathrm{J}_{\mathrm{sc}}\right)$, fill factor $(\mathrm{FF})$ and power conversion efficiency (PCE) values for each set of devices are given in Table 1. It is observed that the $\mathrm{V}_{\mathrm{oc}}$ of both the devices is similar, however the $\mathrm{J}_{\mathrm{sc}}$ increase on increasing the concentration of the CdS NRs. This increase in the $\mathrm{J}_{\mathrm{sc}}$ translates into the increase in the PCE of the device from $1.10 \%$ to $1.16 \%$. This enhancement in the $\mathrm{J}_{\mathrm{sc}}$ is attributed to the improved charge transport from the donor PTB7 to acceptor CdS NRs which is in coherence from the PL quenching studies for the case of PTB7:CdS 1:1 (w/w) ratio as compared to the PTB7:CdS 1:0.5 (w/w) ratio.

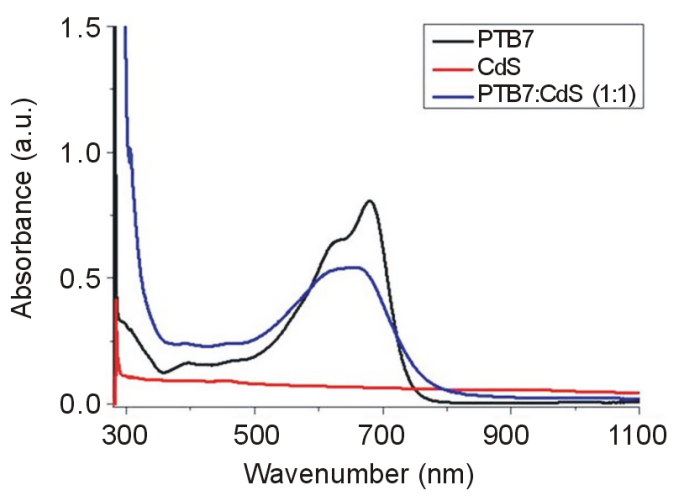

(a)

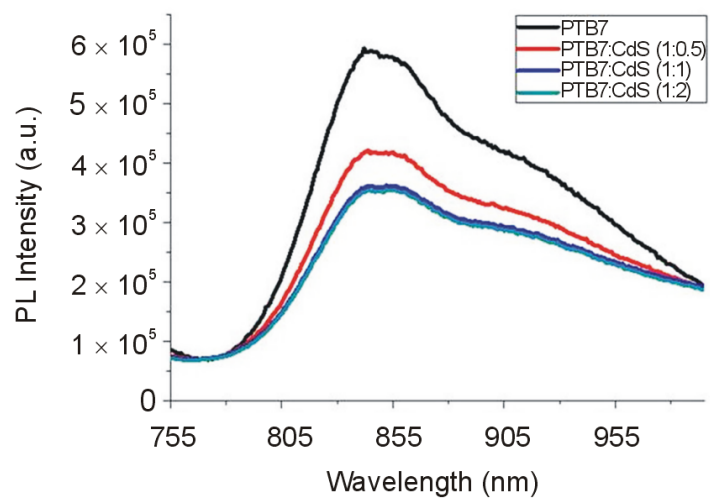

(b)

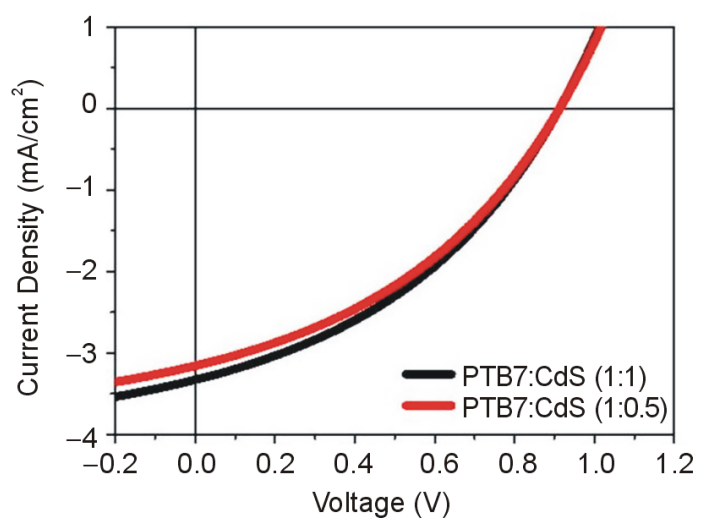

(c)

Figure 3. (a) UV-Visible spectra of PTB7, CdS NRs, PTB7:CdS NRs (1:1) (w/w) ratio, showing modulation of band gap of the PTB7; (b) Photoluminescence quenching study of the PL spectra of the PTB7 by the CdS NRs; (c) $J$ - $V$ characteristics of the HSC device.

Table 1. Device parameters from PTB7:CdS PSCs measured under illumination intensity of $1000 \mathrm{~W} / \mathrm{m}^{2}$.

\begin{tabular}{ccccc}
\hline Devices & $\begin{array}{c}\mathrm{J}_{\mathrm{sc}} \\
\left(\mathrm{mA} / \mathrm{cm}^{2}\right)\end{array}$ & $\begin{array}{c}\mathrm{V}_{\text {oc }} \\
(\mathrm{V})\end{array}$ & $\begin{array}{c}\mathrm{FF} \\
(\%)\end{array}$ & $\begin{array}{c}\eta \\
(\%)\end{array}$ \\
\hline $\begin{array}{c}\text { PTB7:CdS } \\
(1: 0.5)\end{array}$ & 3.25 & 0.91 & 37.5 & 1.10 \\
$\begin{array}{c}\text { PTB7:CdS } \\
(1: 1)\end{array}$ & 3.44 & 0.91 & 37.0 & 1.16 \\
\hline
\end{tabular}




\section{Conclusion}

We successfully demonstrated a green approach to synthesizing BHJ active layer by in-situ growth of CdS NRs in efficient low band gap polymer PTB7 matrix by solvothermal process. We were able to modulate the band gap of PTB7 via coordination bond formation of the functional groups of the polymer with the cadmium. This leads to efficient charge transport from the PTB7 to the CdS NRs. We were able to achieve high $\mathrm{V}_{\text {oc }}$ of $0.91 \mathrm{~V}$ in the HSC fabricated using the PTB7:CdS NRs donor-acceptor nanocomposite in BHJ configuration. This work has implication in the development of green economical and efficient HSC by using highly controlled synthetic process.

\section{Acknowledgements}

The authors thank the director, NPL, for his kind support in this R \& D work. R. K. B. thanks Vice Chancellor and Director, IGNOU, Delhi. Authors are also thankful to DST, Govt. of India, for providing financial support under the India-UK joint initiative project entitled "Advancing the efficiency and production potential of excitonic solar cells (APEX)”.

\section{References}

[1] Mohanty, D. (2013) Study of Charge Transport and Device Properties in Low Band Gap Polymer PBDTTPD Based Nanostructure Materials for Solar Cell Applications. M.Tech Thesis, CSIR-National Physical Laboratory, \& Academy of Scientific \& Innovative Research, New Delhi.

[2] Ren, S., Chang, L.-Y., Lim, S.-K., Zhao, J., Smith, M., Zhao, N., Bulovic, V., Bawendi, M. and Gradecªk, S. (2011) Inorganic-Organic Hybrid Solar Cell: Bridging Quantum Dots to Conjugated Polymer Nanowires. Nano Letters, 11, 3998-4002. http://dx.doi.org/10.1021/nl202435t

[3] Dowland, S., Lutz, T., Ward, A., King, S.P., Sudlow, A., Hill, M.S., Molloy, K.C. and Haque, S.A. (2011) Direct Growth of Metal Sulfide Nanoparticle Networks in Solid-State Polymer Films for Hybrid Inorganic-Organic Solar Cells. Advanced Materials, 23, 2739-2744. http://dx.doi.org/10.1002/adma.201100625

[4] Kwak, W.-C., Kim, T.G., Lee, W., Han, S.-H. and Sung, Y.-M. (2009) Template-Free Liquid-Phase Synthesis of HighDensity CdS Nanowire Arrays on Conductive Glass. The Journal of Physical Chemistry C, 113, 1615-1619. http://dx.doi.org/10.1021/jp809365z

[5] Wang, L., Liu, Y., Jiang, X., Qin, D. and Cao, Y. (2007) Enhancement of Photovoltaic Characteristics Using a Suitable Solvent in Hybrid Polymer/Multiarmed CdS Nanorods Solar Cells. The Journal of Physical Chemistry C, 111, 95389542. http://dx.doi.org/10.1021/jp0715777

[6] Zhong, M., Yang, D., Zhang, J., Shi, J., Wang, X. and Li, C. (2012) Improving the Performance of CdS/P3HT Hybrid Inverted Solar Cells by Interfacial Modification. Solar Energy Materials and Solar Cells, 96, 160-165. http://dx.doi.org/10.1016/j.solmat.2011.09.041

[7] Leventis, H.C., King, S.P., Sudlow, A., Hill, M.S., Molloy, K.C. and Haque, S.A. (2010) Nanostructured Hybrid Polymer-Inorganic Solar Cell Active Layers Formed by Controllable in Situ Growth of Semiconducting Sulfide Networks. Nano Letters, 10, 1253-1258. http://dx.doi.org/10.1021/nl903787j

[8] Lebeau, B. and Innocenzi, P. (2011) Hybrid Materials for Optics and Photonics. Chemical Society Reviews, 40, 886906. http://dx.doi.org/10.1039/c0cs00106f

[9] Dong, H., Zhu, H., Meng, Q., Gong, X. and Hu, W. (2012) Organic Photoresponse Materials and Devices. Chemical Society Reviews, 41, 1754-808. http://dx.doi.org/10.1039/c1cs15205j

[10] Bhardwaj, R.K., Kushwaha, H.S., Gaur, J., Upreti, T., Bharti, V., Gupta, V., Chaudhary, N., Sharma, G.D., Banerjee, K. and Chand, S. (2012) A Green Approach for Direct Growth of CdS Nanoparticles Network in Poly(3-hexylthiophene2,5-diyl) Polymer Film for Hybrid Photovoltaic. Materials Letters, 89, 195-197. http://dx.doi.org/10.1016/j.matlet.2012.08.071

[11] Bhardwaj, R.K., et al. (2014) In-Situ Growth of CdS Nanorods in PTB7 by Solvothermal Process for Hybrid Organic Inorganic Solar Cell Applications. Physics of Semiconductor Devices. Springer International Publishing, Switzerland, 331-333.

[12] Bharti, V., Jain, S., Gaur, J., Sonania, A., Mohanty, D., Sharma, G.D. and Chand, S. (2014) Sustainable Organic Polymer Solar Cells Using $\mathrm{TiO}_{2}$ Derived from Automobile Paint Sludge. Physics of Semiconductor Devices, Springer International Publishing, Switzerland, 395-397.

[13] Mohanty, D., Bharti, V., Gaur, J., Bhardwaj, R., Sharma, G.D. and Chand, S. (2014) Charge Transport Studies in Pure and CdS Doped PBDTTPD:CdS Nanocomposite for Solar Cell Application. Physics of Semiconductor Devices, 
Springer International Publishing, Switzerland, 323-325. http://dx.doi.org/10.1007/978-3-319-03002-9_81

[14] Gaur J., Jain, S., Chand, S. and Kaushik, N.K. (2014) Tin Sulfide Nanoparticle Synthesis from Waste Waters. American Journal of Analytical Chemistry, 5, 50-54. http://dx.doi.org/10.4236/ajac.2014.52008

[15] Gaur, J., Jain, S., Bhatia, R., Lal, A. and Kaushik, N.K. (2013) Synthesis and Characterization of a Novel Copolymer of Glyoxal Dihydrazone and Glyoxal Dihydrazone Bis(dithiocarbamate) and Application in Heavy Metal Ion Removal from Water. Journal of Thermal Analysis and Calorimetry, 112, 1137-1143.

[16] Huynh, W.U., Dittmer, J.J. and Alivisatos, A.P. (2002) Hybrid Nanorod-Polymer Solar Cells. Science, 295, $2425-2457$. http://dx.doi.org/10.1126/science.1069156

[17] Dayal, S., Kopidakis, N., Olson, D.C., Ginley, D.S. and Rumbles, G. (2010) Photovoltaic Devices with a Low Band Gap Polymer and CdSe Nanostructures Exceeding 3\% Efficiency. Nano Letters, 10, 239-242. http://dx.doi.org/10.1021/nl903406s

[18] Huynh, W.U., Peng, X.G. and Alivisatos, A.P. (1999) CdSe Nanocrystal Rods/Poly(3-Hexylthiophene). Composite Photovoltaic Devices. Advanced Materials, 11, 923-927.

[19] Sun, B.Q., Snaith, H.J., Dhoot, A.S., Westenhoff, S. and Greenham, N.C. (2005) Vertically Segregated Hybrid Blends for Photovoltaic Devices with Improved Efficiency. Journal of Applied Physics, 97, Article No. 014914. http://dx.doi.org/10.1063/1.1804613

[20] Zhou, Y., Li, Y.C., Zhong, H.Z., Hou, J.H., Ding, Y.Q., Yang, C.H. and Li, Y.F. (2006) Hybrid Nanocrystal/Polymer Solar Cells Based on Tetrapod-Shaped CdSe $\mathrm{Te}_{\mathrm{x}-\mathrm{x}}$ Nanocrystals. Nanotechnology, 17, 4041-4047.

[21] Wang, L., Liu, Y.S., Jiang, X., Qin, D.H. and Cao, Y. (2007) Enhancement of Photovoltaic Characteristics Using a Suitable Solvent in Hybrid Polymer/Multiarmed CdS Nanorods Solar Cells. The Journal of Physical Chemistry C, 111, 9538-9542. http://dx.doi.org/10.1021/jp0715777

[22] Kaito, C., Saito, Y. and Fujita, K. (1987) A New Preparation Method of Ultrafine Particles of Metallic Sulfides. Japanese Journal of Applied Physics, 26, L1973-L1975.

[23] Baker, D.R. and Kama, P.V. (2009) Photosensitization of $\mathrm{TiO}_{2}$ Nanostructures with CdS Quantum Dots: Particulate versus Tubular Support Architectures. Advanced Functional Materials, 19, 805-811. http://dx.doi.org/10.1002/adfm.200801173

[24] Wright, M. and Uddin, A. (2012) Organic-Inorganic Hybrid Solar Cells: A Comparative Review. Solar Energy Materials \& Solar Cells, 107, 87-111. http://dx.doi.org/10.1016/j.solmat.2012.07.006

[25] Leventis, H.C., King, S.P., Sudlow, A., Hill, M.S., Molloy, K.C. and Haque, S.A. (2010) Nanostructured Hybrid Polymer-Inorganic Solar Cell Active Layers Formed by Controllable in Situ Growth of Semiconducting Sulfide Networks. Nano Letters, 10, 1253-1258. http://dx.doi.org/10.1021/nl903787j

[26] Dowland, S., Lutz, T., Ward, A., King, S.P., Sudlow, A., Hill, M.S., Molloy, K.C. and Haque, S.A. (2011) Direct Growth of Metal Sulfide Nanoparticle Networks in Solid-State Polymer Films for Hybrid Inorganic-Organic Solar Cells. Advanced Materials, 23, 2739-2744. http://dx.doi.org/10.1002/adma.201100625

[27] Karlin, K.D. (2005) Progress in Inorganic Chemistry. 53, John Wiley \& Sons, Inc., Hoboken, New Jersey. 
Scientific Research Publishing (SCIRP) is one of the largest Open Access journal publishers. It is currently publishing more than 200 open access, online, peer-reviewed journals covering a wide range of academic disciplines. SCIRP serves the worldwide academic communities and contributes to the progress and application of science with its publication.

Other selected journals from SCIRP are listed as below. Submit your manuscript to us via either submit@scirp.org or Online Submission Portal.
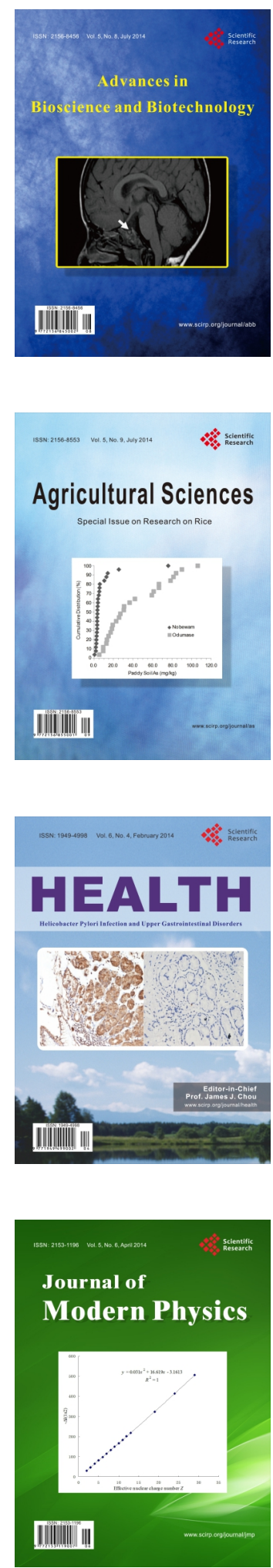
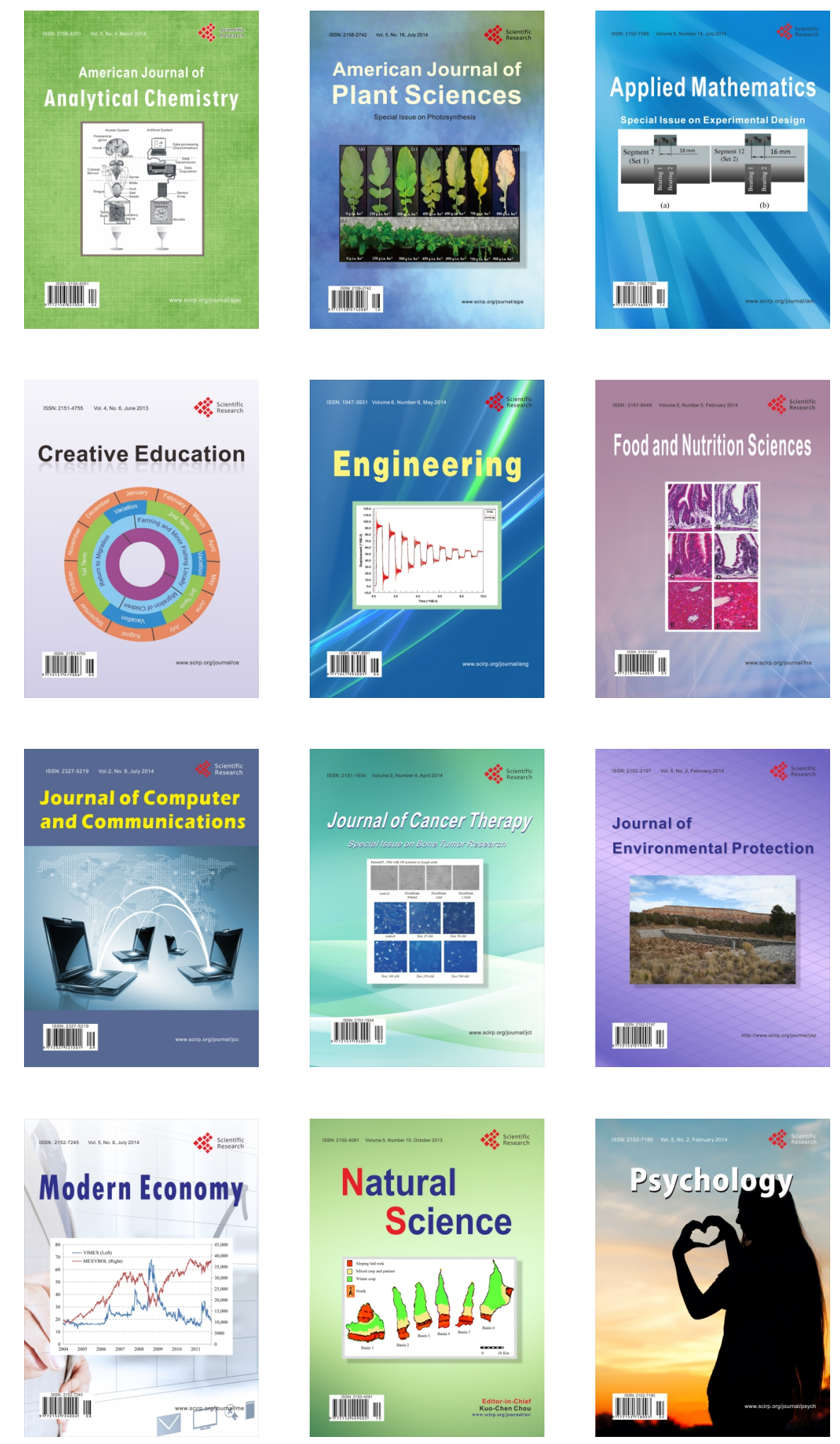